\title{
Consideration of the loading of the traffic lines in the design of automobile roads
}

\author{
Denis Nikolenko ${ }^{1 *[0000-0002-7119-002 X]}$, Maxim Nikolenko ${ }^{1[0000-0002-3500-7187]}$, and Anastasiya \\ Filippova ${ }^{1[0000-0002-8838-105 X]}$
}

${ }^{1}$ Don State Technical University, 344002, Gagarin Square, Rostov-on-Don, Russia

\begin{abstract}
The article focuses on the importance of the strength and durability of highways due to the projected increase in freight traffic. It also describes the consequences of uneven distribution of loads in traffic lanes, depending on the prevailing traffic in each lane. The studies, that were carried out earlier by various scientists, were taken into account, thankfully to which results were obtained on the composition of the traffic flow, the difference in the loading of road pavements, as well as the stressstrain state of road structures. As a result, a model that reflects the dependence of the influence of the speed of movement of vehicles on the dynamic deformation of structures, was developed. Consequently, a number of design solutions were established to ensure the required strength of all structures.
\end{abstract}

Keywords: road design, load distribution, economic efficiency, increasing the strength.

\section{Introduction}

The main goal of the article is to investigate the dynamic stress-strain state of road structures, taking into account the influence of speed modes and traffic composition to optimize decisions in the design of road pavements of highways.

In recent years, the volumes of cargo transportation carried out by carriers in intercity as well as international traffic have been growing rapidly. According to the forecast of transport development, by 2025-2030 the share of freight traffic will increase to about 30$40 \%$. A significant increase in the carrying capacity and permitted speed of modern vehicles requires an increase in the throughput of roads, and as a result, an increase in the length of the highway network [1].

Therefore, the construction of highways that meet the increased requirements for strength and durability is currently of great importance in Russia, and the determination of ways to optimize the design of highways is an important and timely task as well [2].

It is known that the distribution of traffic intensity on different lanes of highways is not the same [3]. In the existing regulatory documents, when designing multi-lane roads, a coefficient is used that takes into account the number of traffic lanes and the distribution of traffic along them.

* Corresponding author: d.a.nikolenko@mail.ru 
However, the unevenness of the intensity along the lanes is accompanied by a change in the composition of the traffic flow and speed. Consequently, along the leftmost lane the highways with a multi-lane carriageway permit the speed of over $100 \mathrm{~km} / \mathrm{h}$ (the traffic speed in some sections reaches $140-150 \mathrm{~km} / \mathrm{h}$ ). Heavy-duty vehicles (trucks) prevail along the rightmost lane with an average speed of $70-80 \mathrm{~km} / \mathrm{h}$. The high-speed mode of movement in the middle lanes has an intermediate value [4].

Thus, the loading of traffic lanes is different, and, consequently, the design of road surface should be carried out with the account of characteristics of the loading in each lane.

In this regard, the solution of the problem of identifying the dependence of the influence of speed modes and the composition of the flow on the dynamic loading of road structures has acquired particular relevance [5]. The research of the real dynamic stress-strain state (SDS) of road structures on multi-lane highways will make it possible to develop optimal design solutions that reduce construction costs for a given durability of road structures [6].

A review and study of the design features of road structures for multi-lane highways was carried out. According to the regulatory document in force in the Russian Federation, the calculation and design of road pavements of highways has almost no difference with the principles of design and calculation of pavements of highways of the general network [7]. However, the average cost of building highways is several times higher than the cost of roads of lower technical categories.

In conditions of limited resources, interest in the problem of minimizing the cost of building highways and, in particular, road pavements, is natural, since in the general complex of structures on highways, road surfaces are the most capital-intensive element [8]. The works of a great amount of scientists are devoted to solving the problem of optimizing the designs of road structures and highways. Among those scientists are A. M. Krivissky, B. S. Radovsky, V. F. Babkova, M. B. Korsunsky, N. N. Ivanova, M. L. Goldenberg and others (in our country); C. Brown, W. Hudson, D. Burmister and others (abroad). They carried out numerous studies and proposed various principles of rational design. Special attention should be paid to the rational design of road structures of multilane highways along traffic lanes [9].

\section{Materials and methods}

It has been established that the peculiarities of the differences in the loading of road pavements of different lanes of motorways are not only in the unevenness of the distribution of intensity along the lanes, but also in the difference in speed modes of movement and the composition of the transport [10].

The study of the composition of the traffic flow of multi-lane highways was carried out by V. F. Babkov, A. N. Krasnikov, V. V. Silyanov, A. Ya. Khomyak, Ya. E. Varna, M. G. Goryachev, G M. Hasanov. Regularities of the distribution of the flow along the width of the carriageway were obtained, the speed of movement and the composition of the traffic flow along the lanes were determined [11].

The study of the dynamic stress-strain state of road structures is devoted to the works of A. V. Smirnova, S. K. Iliopolova, B. S. Radovsky, V. P. Matua, A. K. Privarnikova, A. S. Supruna, A. G. Malofeev, J. Elliott, F. Movenzade and others [12].

The research results indicate that the traffic speed is one of the main factors that determine the stress-strain state of the road pavement.

In this regard, the task is to identify the dependence of the influence of speed modes and the composition of the traffic flow on the dynamic stress-strain state of road structures of automobile highways, taking into account the nature of the distribution by traffic lanes [13]. To implement the set task, the necessity of both creating a model describing the stress- 
strain state of a road structure under the action of a moving car and conducting a number of experimental studies aimed at confirming the results of modeling is substantiated [14].

A mechanics - mathematical model of the «road structure - soil» system has been developed using the finite element method to study the effect of vehicle speed on the dynamic deformation of road structures [15].

The finite element method is the most common and versatile method for analyzing the stress-strain state (SSS) of complex systems. The essence of this method lies in the fact that a structural model of a complex geometric shape is subdivided into small parts (finite elements) of a relatively simple shape, within which an approximate solution is sought. The solution of the problem using the FEM consists of the following main stages: creation of the geometry of the model; assignment of physical parameters to the elements of the model; subdivision into a mesh of finite elements; application to the finite conditions model; numerical solution of the system of equations [16].

The geometry of the proposed design model is a multilayer system (Fig. 1). It is possible to take into account both the physical and mechanical properties of individual elements, such as elastic moduli, Poisson's ratios, density, as well as their geometric parameters (number of layers, layer sizes). Thus, the software product allows for calculations for structures that differ in strength and geometrical characteristics of structural layers [17].

As the basis the road structure corresponding to the sections of the M4 «Don» highway with vibration accelerometers embedded in the layers of the road structure during the construction process was taken. That made it possible to compare the results obtained in the modeling process with the results determined experimentally. The impact is presented in the form of an impulse, which is applied to the surface of the «road structure - soil» system, at the points of contact with the road surface of the wheels of the simulated car [18].

The load corresponding to the passage of trucks was taken for the calculations. In addition, the effects of light trucks, medium trucks, heavy trucks and very heavy vehicles were modelled [19]. Taking into account the fact that the flow of cars moving at high speeds prevails on the inner lanes of highways, it was decided to set the parameters of the impact of a passenger car at different speeds [20].

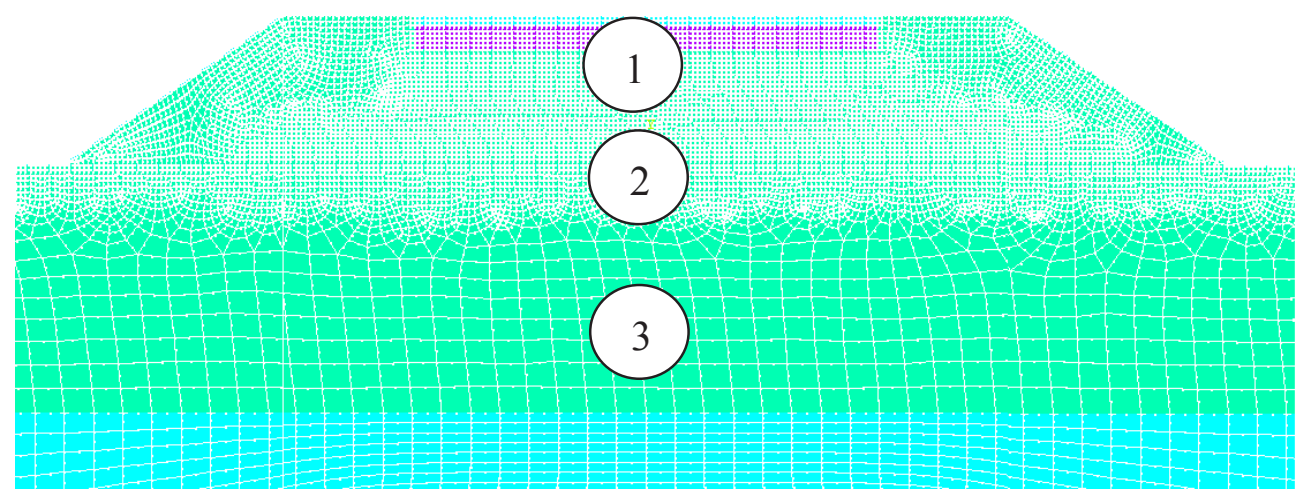

Fig. 1. The investigated system «road structure - soil»: 1 - the design of the road surface; $2-$ compacted subgrade; 3 - layered half-space.

\section{Results}

Taking the developed model as the basis, the calculation of the dynamic stress-strain state of the elements of the «road structure - soil» system from the impact of various types of vehicles at different speed conditions $(\mathrm{V}=40 \div 160 \mathrm{~km} / \mathrm{h})$ has been carried out. The 
calculation results (Fig. 2) are reflected by the dependences of the maximum values of the obtained amplitude-time characteristics of the stress-strain state of the elements of the «road structure - soil» system $(U, \dot{U}, \ddot{U}, \sigma)$ on the speed of the simulated vehicle (40 $\div 160 \mathrm{~km} / \mathrm{h}$ )

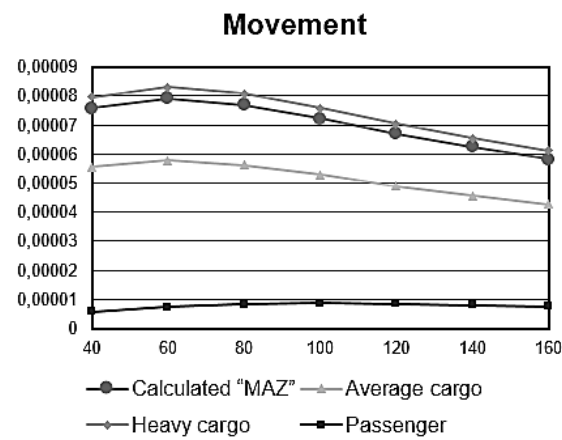

Y-axis values - displacement amplitude, $\mathrm{m}$; $\mathrm{X}$-axis values - speed, $\mathrm{km} / \mathrm{h}$

Speeds

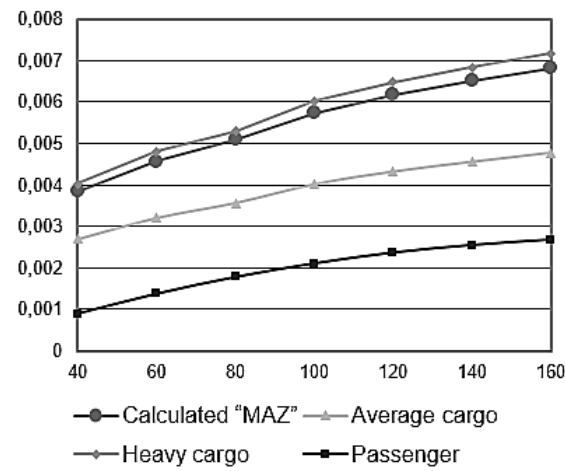

$\mathrm{Y}$ - axis values - speed amplitude, $\mathrm{m} / \mathrm{s}$ $\mathrm{X}$ - axis values - speed, $\mathrm{km} / \mathrm{h}$

\section{Acceleration}

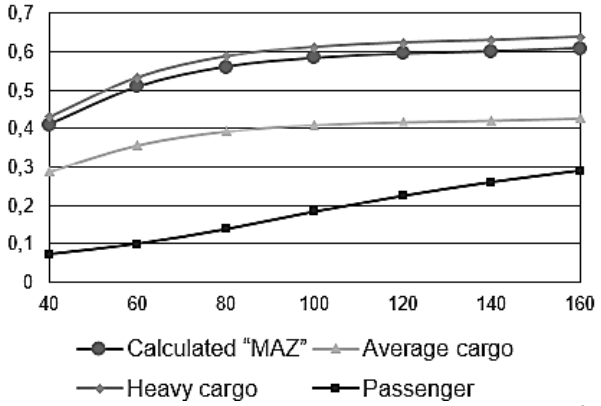

$\mathrm{Y}$ - axis values - acceleration amplitude, $\mathrm{m} / \mathrm{c}^{2}$ $\mathrm{X}$-axis values - speed, $\mathrm{km} / \mathrm{h}$

Tension

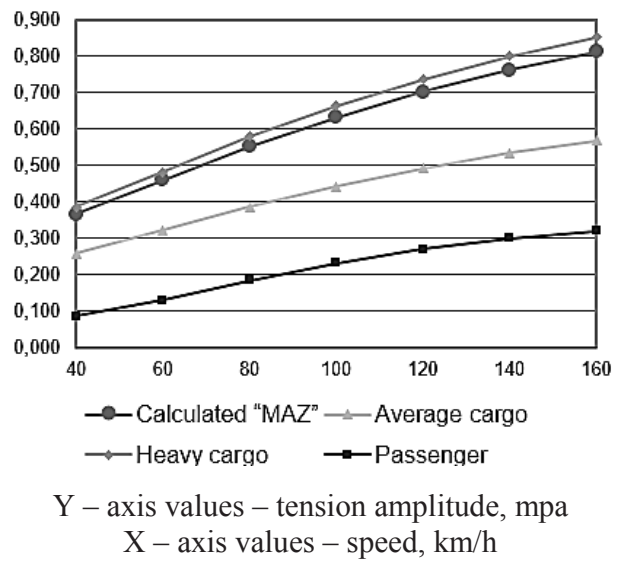

Fig. 2. Characteristics of SSS of the road surface depending on the speed of the simulated vehicles.

\section{Discussion}

It was discovered that with an increase in the speed, there was an increase in the dynamic characteristics in the elements of the road structure. In the case of simulating the movement of a car on a perfectly flat surface, the amplitudes of displacements decrease with increasing speed. However, the dynamism of the impact associated with the unevenness of the pavement leads to the appearance of an extremum of displacements at speeds of 50-70 $\mathrm{km} / \mathrm{h}[21]$.

An increase in tensile stresses in the lower layer of asphalt concrete with an increase in the speed of movement of all types of cars, including passenger cars, was established [22].

A calculation method has been developed that makes it possible to take into account the uneven loading of various traffic lanes and design a road structure that is resistant to fatigue failure from the action of vehicles moving both along the outer and inner lanes of the highway [23]. To ensure the strength of the entire structure according to the criterion of 
permissible elastic deflection without excess strength on the inner traffic lanes, the following design solutions are proposed:

- reinforcement of the asphalt concrete surface of the inner lanes of highways with a polymer mesh;

- reinforcement of the subgrade soil of the extreme traffic lanes with geo-synthetic gratings;

- reinforcement of the base layers of the extreme strips with inorganic and complex binders;

- application of polymer-reinforced and complex-modified mixtures in asphalt-concrete pavements of internal traffic lanes;

- the use of polymer additives in asphalt concrete mixtures.

\section{Conclusions}

It is known that in foreign methods of designing road surfaces (for example, in the method of the Shell company), the calculation of the fatigue of the material of the bending layer is considered to be the main aspect for determining the required thicknesses of structural layers. Therefore, it is necessary to apply layer reinforcement methods to increase the durability of the structure.

The use of the proposed design solutions will make it possible to strengthen the weakest structural element in the pavement of the projected lane and to focus on the calculation of the most important criterion for the lane, which is strength.

\section{References}

1. M. A. Nikolenko, Considering the peculiarities of the loading of highway lanes in the design of road surfaces (Dis. cand. of science, 05.23.11, Rostov-on-Don, Russia, 185, 2006)

2. ROSAVTODOR, Guidelines for assessing the strength of non-rigid road pavements. M.: MADI, 2013, ODM 218.2.024-2012

3. E. R.Khafizov, E. A.Vdovin, L. F. Mavliev, A. Yu. Fomin, P. E. Bulanov, Determination of the volume of traffic and speed of movement on the street-road network in Kazan in the framework of the study of a formation of defects on road surfaces, Izvestiya KGASU, 40, 2, 297-302 (2017)

4. SP 243.1326000.2015 Design and construction of highways with low traffic intensity

5. V. N. Azarov, I. V. Stefanenko, N. Yu. Karapuzova, D. A. Nikolenko, Monitoring of Fine Dust Pollution of Urban Air Nearby Highways, International Review of Mechanical Engineering, 12, 8, 657-662 (2018)

6. D. V. Chirva, The influence of elastic-viscous-plastic properties of asphalt concrete on the accumulation of residual deformations during spatial dynamic loading of road structures (Diss. cand. of tech. science, 05.23.11,Volgograd, Russia, 141, 2010)

7. A. P. Vasiliev, M. S. Koganzon, Yu. M. Yakovlev, Development of methods for calculating non-rigid road surfaces, Problems of construction and operation, highways. Collection of scientific works MADI-TU, 16-19 (1998)

8. A. V. Smirnov, A. A. Malyshev, Yu. A. Agalakov, Mechanics of stability and destruction of road structures (SIBADI, Omsk, Russia, 91, 1997)

9. B. S. Radovskiy, Concept of eternal road surfaces (Internet Laboratories Inc., USA)

10. L. F. Mavliev, E. A. Vdovin, N. V. Konovalov, K. R. Khuziahmetova, N. B. Sharapova, Development of road-building material based on gravel-sand-cement 
mixture with optimal granulometric composition, Izvestiya KGASU, 4(50), 435-443 (2019)

11. E. R. Khafizov, E. A. Vdovin, O. N. Ilina, A. Y. Fomin, Researches of physical and mechanical properties macadam concrete on the basis of the polymer-bitumen binders, Izvestiya KGASU, 1(35), 211-214 (2016)

12. M. G. Goryachev, Predicting the operational state of non-rigid road pavements, taking into account the process of accumulation of residual deformations (Diss., PhD: 05.23.11, MADI, Moscow, Russia, 2017)

13. V. P. Matua, L. N. Panasyuk, Forecasting and accounting for the accumulation of residual deformations in road structures (RSBU, Rostov-on-Don, Russia, 372, 2001)

14. A. P. Vasiliev, M. S. Koganzon, Yu. M. Yakovlev, Development of methods for calculating non-rigid road surfaces, Problems of construction and operation, highways. Collection of scientific works MADI-TU, 16-19 (1998)

15. M. A. Zhuravkov, T. A. Makaeva, Mechanics and mathematical models for behavior of the deformable solid and elastic mediums with regard to their internal structure (Belarusian State University, Minsk, 2011)

16. A. N. Tiraturyan, E. V. Uglova, A. A. Lyapin, Studying the energy distribution of the dynamic influences of road transport on the layers of nonrigid pavements, PNRPU Mechanics Bulletin, 2, 178-194 (2017) DOI: 10.15593/perm.mech/2017.2.10

17. E. V. Uglova, Modeling of the dynamic impact of vehicles on road structures of operated highways taking into account the unevenness of the road surface, Far East: highways and safety movement: interuniversity. topics. Sat. scientific. tr., 4, 54-60 (2004)

18. S. K. Iliopolov, Longevity of road constructions in the conditions of dynamic influence of transport (RSBU, 2009)

19. I. I. Egorova, D. I. Erochin, Estimation of road bridges resource indicators based on the analysis of structural changes and damage accumulation in structural elements, Izvestiya KGASU, 4(50), 444-451 (2017)

20. E. V. Uglova, Theoretical and methodological bases for assessing the residual fatigue state of asphalt concrete coatings of highways (Diss., PhD: 05.23.11, Rostov-on-Don, 371, 2009)

21. V. P. Matua, Research of the stress-strain state of road structures taking into account their inelastic properties and spatial loading (Diss., Doctors of technical sciences: 05.23.11, Rostov-on-Donu, 484, 2002)

22. V. P. Matua, L. N. Panasyuk, Prediction and accounting of accumulation of residual strains in the road constructions (RSUC, Rostov-on-Don, 2001)

23. A. P. Lupanov, V. V. Silkin, I. O. Kozikov, O. N. Ilina, Research of the properties of asphalt mixers using soft roofing wastes for the construction and repair of automobile roads and city streets, Izvestiya KGASU, 49(3), 205-210 (2019) 